\title{
Sobre la constitución del saber administrativo
}

Os ocupáis de vuestras riquezas, de vuestra reputación y de los honores; pero no os ocupáis ni de vuestra virtud ni de vuestra alma Platón. Apología de Sócrates

Prof. Juan Pablo Román, Msc. jromanca@eafit.edu.co

Profesor Área Académica de Negociación e Interculturalidad Departamento de Negocios Internacionales Universidad EAFIT

Editor Científico Responsável: Prof. Dr. Roberto Patrus Mundim Pena Professor do Programa de Pós-graduação em Administração da Pontifícia Universidade Católica de Minas Gerais/FDC

Artigo Convidado

\section{Resumen}

El presente artículo trata de cuestionar la constitución del saber administrativo, esto en dos sentidos: en su calidad, preguntándose por su estatuto -teoría, doctrina o ideología; en su origen y crecimiento: como tributario de otros saberes. Se intenta asimismo propiciar una reflexión acerca de la necesidad de reflexionar sobre la necesidad de repensar la aplicación de un conocimiento doctrinario -argumentada la arbitrariedad en su constitución- a realidades sociales con características particulares.

Palabras claves: Administración. Epistemología. Doctrina. Ideología. Crítica.

\begin{abstract}
This paper questions how management has been constituted. On the one hand discussing its status - is it theoretical, ideological or doctrinal knowledge? On the other hand, commenting the excesses on the application of some concepts and techniques, coming from social sciences. Therefore, it tries to enhance a conscious approach, from both academics and practitioners, to the management discipline. The latter regarding the settlement of any management model within a new context.
\end{abstract}

Key word: Administration. Epistemology. Doctrine, Ideology. Critique.

Este escrito quiere exponer algo que para su autor se ha presentado de forma problemática. Es claro que en el momento histórico en el cual nos encontramos muchas definiciones se han hecho obvias, y multiplicidad de recorridos hitorico-teóricos cuando menos ya se han comenzado a allanar. A partir del camino sugerido por la obra de una serie de autores representativos de algunas de la ciencias que conforman la teoría administrativa, y 
dejando en suspenso cualquier definición/fórmula de la realidad que ha sido nombrada con el apelativo Administración, trataré de construir una respuesta-desde mi relación particular con dicho campo- a la pregunta que titula el texto.

Cuando se habla de administración se trata de hecho de una realidad. Ya Michel Foucault ha puesto en evidencia las relaciones entre verdad, saber y poder, que indican que un discurso determinado ejerce una suerte de encantamiento sobre los individuos que se articulan en torno a él (FOUCAULT, 2004, p. 91). Y es que los discursos, a partir de las prácticas que les corresponden, son la estrella del norte de las experiencias de quienes se encuentran inscritos en ellos.

Evitando - por claras razones- un abordaje directo del plano histórico de esa realidad que nos ocupa, y siendo consecuente con la anterior introducción, se trata aquí de comentar algunas vertientes teóricas tributarias de la actualidad de la cuestión, así como ciertas relaciones entre la administración como saber y la realidad, no solo empresarial sino también cotidiana -si bien es necesario reconocer que el establecimiento de una frontera tal -entre lo administrativo y lo cotidiano- es tal vez solo imaginario (MUÑOZ, 2007, p. 9).

Con lo anterior se quiere sugerir de manera más o menos implícita la orientación este intento personal de definición. Es que como cualquier producción de un sujeto, no escapa a un abanico de referentes que va desde lo pasional hasta lo que se supone plenamente intelectual $^{1}$. Específicamente se trata entonces aquí de un ejercicio de interpretación teniendo el texto "examinado" - la administración- la siguiente característica: tanto la realidad delineada por el saber correspondiente-la empresa-, como la disciplina que le confiere un espacio dentro del edificio del conocimiento -aunque este espacio es en sí mismo una realidad y la delimitación es como la anterior igualmente ficticia-, son dinámicas altamente complejas.

Son campos de alta complejidad no solo por la multiplicidad de elementos intervinientes, sino porque también estos aspectos, además de impactar en la experiencia general del ser humano, son a su vez impactados por esta (MORIN, 1992, p. 21). De ello se desprende la posibilidad de afirmar que existe cierto margen de equivocación al establecer por antonomasia LA definición de LA administración. Ella no debe ser especificada a partir de un solo modelo de administración para contextos netamente diferenciados. De lo contrario se estaría utilizando con dicho fin un saber extraído de una realidad única, a través de técnicas probablemente inaplicables, para intentar solucionar problemáticas parcial o

\footnotetext{
1 “...el conocimiento de un sujeto que lleva en sí igualmente genocentrismo, etnocentrismo, sociocentrismo, es decir diversos centros-sujetos de referencia” (MORIN, 1992, p. 22)
} 
totalmente desconocidas por los creadores de un modelo de pronóstico reservado ${ }^{2}$.

Es digno de mención que, no solo en las construcciones "teóricas" de autoridades de reconocimiento internacional, sino también ya en las elucubraciones de algunos teóricos/prácticos del ámbito administrativo colombiano de los primeros años del siglo pasado, giraban en torno a este preponderante asunto (MUÑZ, 2007, p 31); antes de que el fenómeno de la globalización empezara a ser pensado por unos como problema, por otros como oportunidad.

En este sentido tampoco pueden pasarse por alto la participación, ignorada o tenida en cuenta solo parcialmente -lo que a su vez depende de un contexto social, político, económico y cultural- de Oliver Sheldon y Melville Dalton. El primero insistiendo en que la administración está históricamente enmarcada. El segundo incluyendo en su práctica investigativa la opción etnográfica (MUÑOZ, 2007, p. 20, 29).

Hasta aquí se pretende presentar la administración como saber que sostiene o debería por lo menos sostener un doble vínculo con una realidad que puede superarla -la modela y debe ser por ella modelada. El primero de ellos fundado de acuerdo a un esquema de relación sujeto -objeto. Aunque no podrían desestimarse totalmente los aportes que las ciencias de la naturaleza han hecho a las disciplinas primordialmente nutridas por las ciencias sociales, la traducción directa de dicho esquema conlleva inexactitudes, incongruencias con respecto a las aspiraciones de exactitud y universalidad propias a las "ciencias nomotéticas"3 .

Ahora bien, más allá de una discusión a propósito del carácter científico de la Administración, que llevaría a la inclusión o exclusión de esta dentro de un grupo privilegiado, realizada probablemente para conseguir el aval de determinada comunidad científica $^{4}$, parece más importante definir -aunque sea en los mismos términos de dicha sobrepuja- la identidad propia de la disciplina administrativa. Si bien caracterizarla como ideográfica supone un descrédito ante la comunidad, por pertenecer la naturaleza de su 'target' a "la realidad humana global" (GUSDORF, 1990. p. 3), implica directamente su inclusión en este tipo de aproximación.

\footnotetext{
${ }^{2}$ Los campeones de un saber no deben olvidar las condiciones de nacimiento del sistema de ideas que los convoca. E. Morin señala ejemplarmente esta dependencia del conocimiento con las siguientes palabras: "[...] el conocimiento está unido por todas partes a la estructura de la cultura, a la organización social, a la praxis histórica". (MORIN, 1992, p. 26)

${ }^{3}$ La expresión, comentada por J. Mardones, es de Wildelband. Este último opone las ciencias nomotéticas, que pretenden la institución de leyes, a las ciencias ideográficas, que están dirigidas a la comprensión de hechos particulares". (MARDONES, 1991, p. 31)

${ }^{4}$ La relación entre la legitimación del conociendo y las comunidad científica es tratada por Thomas Kuhn: "La competencia entre fracciones de la comunidad científica es el único proceso histórico que da como resultado, en realidad, el rechazo de una teoría previamente aceptada o la aceptación de otra". (KUHN, 1994, p. 30)
} 
Es un hecho que la realidad humana, comprendida aquella que se circunscribe con el apellido organizacional, está fuertemente matizada por las potencialidades del lenguaje mismo ${ }^{5}$. Sus elementos, estructurantes de una grandísima porción de la experiencia humana, pueden ser tanto signos y como símbolos. Así, un fenómeno perteneciente a ella puede $-y$ debe- ser tanto explicado como comprendido; a toda costa evitando la mutua suplantación entre la explicación y la comprensión ${ }^{6}$. Por lo tanto la investigación realizada y aquella por realizar dentro de un campo administrativo debe considerarse, trascendiendo el dilema Erklaren vs. Verstehen (MARDONES, 1991, p. 27), teniendo presente el horizonte denominado por Habermas “cuasiexplicación” (MARDONES, 1991, p. 48).

En este sentido, en los términos de Gusdorf, la administración debe seguir un enfoque antropológico filosófico más que uno antropológico científico (GUSDORF, 1990, p. 1). Ello no solo en función de la integración de las vertientes que conforman hasta ahora el saber administrativo, sino porque implica otro acercamiento al "objeto" de interés. Si se observan por ejemplo las consecuencias de la transposición de opciones técnicas creadas en otros campos del conocimiento, con orientación netamente positivista, se descubre que estas han llevado consigo al contexto empresarial una particular división del trabajador, correlato de una objetivación del ser humano que les es necesaria a una aproximación positivista al ser humano.

La aparición de ambas inclinaciones en el conocimiento occidental, especialización y objetivación, pueden ser claramente comprendida si se contrastan los modelos científicos representados por dos de las figuras más prominentes en su evolución. Mientras que la ciencia aristotélica conservaba una aspiración teleológica (MARDONES, 1991, p. 22), mucho más cercana a la sostenida comprensión de las ciencias humanas, la vertiente galileana, partidaria de una cosmovisión mecanicista, supuso en primer término un conocimiento de las leyes (MARDONES, 1991, p. 23) - por oposición a una ley general trascendente- que regularían el funcionamiento de la máquina cósmica. En segundo lugar, el dominio a través de la colección de técnicas (MARDONES, 1991, p. 25) que se desprende del "descubrimiento" de la multiplicidad de leyes reguladoras.

Para comprender este quiebre en el conocimiento europeo, es interesante señalar que

\footnotetext{
${ }^{5}$ E. Morin trata este punto hablando del "Doble poder de las palabras". (MORIN, 1994, p. 171)

${ }^{6}$ Una aproximación que coincide con este punto de vista se encuentra también en el texto de Miguel Martínez que trata acerca de la necesidad de un n uevo paradigma para las ciencias humanas: "Las explicaciones causales..., deberán complementarse con explicaciones "motivacionales" , explicaciones "funcionales", explicaciones "intencionales" y en general con explicaciones que se relacionen con el "significado" que tienen las cosas y las acciones para el ser humano" (MARTINEZ, 1989, p. 25). El subrayado es mío. Cabe esperar que la "explicación” de intenciones y significados está comandada por un interés de comprensión.
} 
ambos avances no hubiesen sido posibles sin la aparición progresiva de los fundamentos medievales de la llamada ciencia galileana. Tómese por ejemplo el nominalismo de Ockham o el empirismo de Alejandro Magno, ambas aproximaciones indicando no solo un énfasis en la materialidad de lo cognoscible sino también el la divisibilidad de la naturaleza ${ }^{7}$.

Respecto a la administración, a todas luces se observa que, como se acaba de sugerir, ella es una heredera del saber medieval y en consecuencia de la ciencia moderna. Burkard Sievers, profesor emérito de la Universidad de Wuppertal, insiste en que, vía la transformación arbitraria de conceptos, la disciplina administrativa hace uso de técnicas originalmente exógenas al campo ${ }^{8}$. Específicamente comenta que por ejemplo el uso de la teoría de la motivación responde a una filosofía plenamente pragmática ${ }^{9}$. Aislada de esta manera, la motivación supone además una reducción de la complejidad social a las insulsas dinámicas de la satisfacción. Este caso muestra además que el desarrollo de la teoría de la administración en ocasiones parece más estar dirigido a sostener intereses sectarios, que a solucionar los efectos - de la sociedad industrial - de fragmentación de la vida, de delimitación entre esta y el trabajo

Se trata de hecho esquemas simplistas de los cuales no podría a ciencia cierta afirmarse que en algún momento de las elucubraciones iniciales, estuviesen dirigidas por un interés de comprensión del “animal humano". Sobrepasando la discusión acerca de si el conductismo, de vocación netamente experimental en sus inicios, manipulador de signos y ambientes ${ }^{10}$ - ¡el ambiente del individuo humano está revestido de símbolos! - está en capacidad para responder preguntas por el hombre y su trabajo, lo que llama la atención es que este ha servido, él mismo utilizando la famosa pirámide de necesidades de Maslow, según la expresión del profesor Sievers para conformar una "administración de portafolio"11.

\footnotetext{
${ }^{7}$ En un comentario acerca de la vida y obra de Ockham, Reale y Antiseri muestran las cuotas del autor medieval al nominalismo y empirismo moderno (REALE; ANTISERI, 1995, p. 535 y 537). A propósito del segundo nótese el siguiente comentario de M. Castillo: "De animalibus, (libro XXII) cuando clasifica las especies atendiendo a sus particularidades y no por orden alfabético porque se debe tratar cada especie separadamente; y en el libroVIII manifiesta su confianza en la disección de los animales para poder conocerlos mejor..." (CASTILLO, 1996, p. 95). Los subrayados son míos.

${ }^{8}$ El profesor Sievers ofreció una conferencia el 8de octubre de 2007 en la Universidad EAFIT. Esta giró en torno a su artículo "Motivación como sustituto del significado".

${ }^{9}$ El Profesor Iván Darío Toro comentaba en una de las sesiones del Seminario de Epistemología (Maestría en ciencias de la Administración, 2007-2) que el pragmatismo norteamericano contiene una fuerte herencia del empirismo europeo.

${ }^{10}$ Pavlov, Thorndike, Watson y compañía son dignos seguidores del precursor Alejandro Magno. Ver n. 7 de este mismo escrito. Remito a un comentario de la obra de Pavlov que resume la inclinación de su obra y de la de sus continuadores directos y herederos conductistas: COLECTIVO. El aporte de Pavlov al desarrollo de la medicina. Buenos Aires, Psifue, 1957.

${ }^{11}$ Esta expresión fue utilizada por el Profesor Sievers en la misma conferencia. De otro lado debo aclarar que la explicación de la relación entre conductismo y la teoría de Maslow que se haya aquí, no fue explicitada en la conferencia.
} 
Igualmente no se puede descartar que repetidamente, desde el ángulo del establishment, se trate a conveniencia la organización como subconjunto de la vida en sociedad; en algunos casos haciendo aparecer la vida en la empresa como parte de la vida cotidiana de los trabajadores. De allí que se produzcan los excesos en el transporte -tal cual una mercancía que traspasa inalterable fronteras geográficas, legales, sociales, culturales- de herramientas y elucubraciones de las ciencias sociales a la teoría y práctica administrativas. Es que por ejemplo la moda de la responsabilidad social se trata, y no en pocas ocasiones, de conveniencia. De hecho los móviles y objetivos que procuran dicha traducción literal de conceptos y técnicas dejan ver, sobre todo en las consecuencias, la indolencia (consentida o proyectada pero igualmente dañina) ante los efectos nocivos tanto dentro como fuera de la empresa $^{12}$.

Aunque quizás en términos decididamente pragmáticos, se ha insistido enfáticamente en que este punto - RSC - debe ser tocado. Esto en algunos de los más prestigiosos círculos académicos y prácticos de la administración (BENNIS; O'TOOLE, 2005). Sin embargo la cuestión ética debe guardarse de los mismos intereses que han hecho realidad la apropiación ecléctica, por parte de la disciplina administrativa y como si fuese un agujero negro, de conocimientos provenientes de las ciencias sociales y naturales.

Con respecto a las técnicas importadas desde este último grupo de conocimientos, si bien confrontadas con las paradojas que resultan de su aplicación, es innegable que ellas por medio de su aplicación tienen efectos en la vida de los hombres (MOUCHOT, 1990, p. 12). Un efecto palpable y específico para el caso, recién comentado en términos de objetivación y escisión, es la conducción de las empresas de acuerdo a una concepción típicamente económica del ser humano.

Sin importar el grado de efectividad de las herramientas administradas, muchas veces aplicadas sin un convencimiento total acerca de su validez y confiabilidad, aun si el administrador no considera las consecuencias de las decisiones o considera que ellas recaen solo sobre los empleados, él mismo sufre el imperativo de un discurso que gira en torno al homúnculo económico. En otras palabras, no puede evitar el siguiente hecho vivido, aun si lo quiere ignorar: aquel que acepta sin la mínima reflexión crítica las demandas que el saber administrativo le propone, queda a merced a nivel de sus actos, de su palabra y de su pensamiento, del poder que dicha aceptación supone en él (FOUCAULT, 2004).

\footnotetext{
${ }^{12} \mathrm{Y}$ uno se pregunta por las causas eficientes $\boldsymbol{y}$ finales de las organizaciones (MARDONES, 1991, p. 22). Si la experiencia muestra que la organización es una realidad compleja por la multiplicidad de elementos y dinámicas que le dan existencia, estratégicamente habría que sobrepasar la forma y la materia, en otras palabras lo estático (REALE; ANTISERI, 1995, p. 166). Ello se ajustaría más a una verdadera responsabilidad social.
} 
Dicho poder, junto con sus consecuencias puede ser tratado en términos psicológicos.

El accionista, el gerente y el administrador, al igual que el trabajador - la misma definición implica una cosificación del ser humano - se convierten gracias al sistema en una serie de facetas. Piénsese específicamente en la de consumidores, con las angustias y goces que generan por ejemplo las imágenes ideales y ficticias que se le presentan ${ }^{13}$.

De otro lado, y dando crédito a la sabiduría de los Antiguos - específicamente a Aristóteles -, debe recordarse que la identificación de la felicidad con la acumulación de riquezas hace parte de una vida "contra natura", por que esta debería ser un medio y no un fin en sí mismo (REALE; ANTISERI, 1995, p. 184).

La corta reseña propuesta hasta aquí sobre la inclusión de conocimientos y técnicas propone al autor de estas líneas continuar con la idea central del texto, ya no centrándose en quienes la desean, promulgan y cumplen con o sin reservas, sino a nivel del saber administrativo mismo: La administración como cuerpo de conocimientos, en los términos de E. Morin y según lo recopilado hasta aquí, está más del lado de la doctrina que de la teoría; y está tomada por una ideología ${ }^{14}$.

Esta afirmación supone que habría que descartar por anticipado el carácter de teoría. La férrea resistencia al cambio que experimenta el saber ante los fenómenos organizacionales que escapan a la "lógica" administrativa ${ }^{15}$, se manifiesta por oposición en la trasformación o sincretismo de las técnicas aportadas por otros campos del conocimiento ${ }^{16}$, la disociación entre las primeras y los segundos - que facilita su asimilación dentro de la parafernalia de administrativa- y el reciclaje de las palabras de los supuestos fundadores del discurso administrativo. Estos efectos son características propias de una doctrina, a la vez que son ajenos a una teoría propiamente dicha ${ }^{17}$. Suplementariamente, es evidente en la palabra de los

\footnotetext{
${ }^{13}$ Así como el psicoanálisis desde su fundación ha señalado como dinámica de la vida humana el deseo, no ha olvidado la pulsión de muerte. La diferencia entre el yo y el ideal supone una dialéctica en la cual el Superyo hace las veces del amo (FREUD, 2001, p. 103). La cosificación masoquista que esto implica conlleva una ganancia o cuota innegable de goce.

${ }^{14}$ Rodrigo Muñoz cita el concepto "doctrina-praxis" del profesor O. Aktouf (MUÑOZ, 2006, p. 190). Trato de desarrollar de manera particular la idea, esto desde mi participación en el ya referenciado Seminario de Epistemología. Es aquí que radica la relativa novedad del escrito.

${ }^{15}$ Johansen (1992) señala que en la vida real las organizaciones están compuestas por tres sistemas: social, formal e informal. El primero funciona como soporte de la organización, el segundo caracteriza la organización y el tercero estaría ausente en una organización ideal - por lo tanto sería equivalente a la reacción de la organización ante problemas, necesidades, etc.

16 Ver aquí arriba el comentario acerca de la simplísima adaptación de la teoría de Maslow al esquema psicológico conductista.

${ }^{17}$ A propósito de los sistemas de ideas en general, E. Morin propone que uno de los tipos es la doctrina que “...no tiene ninguna necesidad de buscar este acuerdo (con la realidad exterior), que ella cree haber establecido de una vez por todas, atrae las necesidades de certeza, los deseos de absoluto, la búsqueda obsesiva de la palabra rectora, y de todo ello se nutre con avidez. Esta regeneración exterior estimula una fuente regenerativa interna, que es la palabra sacralizada de sus fundadores..." (MORIN, 1992, p. 138). Los paréntesis y
} 
algunos practicantes y "académicos" un continuo que va de la indiferencia complaciente al rechazo rotundo; basta mirar la marcada inclinación seudo científica de los artículos plasmados en las principales publicaciones del campo.

Si los sistemas de ideas presentan todos una resistencia al cambio, la teoría, aunque sin resignar unos criterios fundamentales, establece una relación mucho más dialéctica con la experiencia. De otro lado, y cabe esperar que una teoría no se preste para ello por su vocación crítica, una doctrina da origen a una ideología a partir de una crítica dirigida a ella, o es creada como sustento para un sistema ideológico (MORIN, 1992, p. 145). En este sentido, aunque E. Morin no la menciona en el pasaje citado, en el cual incluye la ideología racionalista, cientificista y marxista, quiero avanzar que la administración, como se conoce actualmente a nivel global, se debe a una ideología netamente capitalista. Y se debe en dos sentidos de la palabra:

En el primero - que remite a su origen- pues ella se cristaliza después de la aparición de la configuración industrial de la sociedad occidental, que a su vez tiene sus raíces en el nacimiento del insipiente capitalismo europeo del siglo XVI ${ }^{18}$. Lo anterior podría contrariar la noción normalizada que se tiene de las Luces. Si bien, es imposible pasar por alto que el conocimiento humano solo adquirió difícil y gradualmente una independencia con respecto a la ideología cristiana, sin embargo sería faltar a la historia desconocer que, a medida que se cristalizaba el sueño de los modernos de hacer de él un instrumento aséptico de control y dominación de la naturaleza, la actitud servil de este ${ }^{19}$ paulatinamente encontró unos nuevos ejes ideológicos de referencia: estado, la industria, el ejército (MORIN, 1992, p. 62). Así, la disciplina administrativa podría considerarse también como un paquete de técnicas sustentado desde un sistema de ideas de carácter doctrinario

El otro sentido de deber-se que interesa aquí es aquel que remite a una deuda. Como acaba de sugerirse, la administración desde entonces se debe en tanto ha sido la servidora de los propietarios. Si se revisa un poco la historia de la disciplina se puede constatar en su funcionamiento real, por encima de la oposición - generalmente ignorada - de algunos pioneros de la administración a esta conveniencia, ha beneficiado al linaje de los "cómodos" accionistas contemporáneos. Y los ha beneficiado primordialmente según la ideología capitalista, mas no exclusivamente en los términos que componen dicho discurso.

resaltados son míos.

${ }^{18}$ Los detalles se encuentran claramente descritos en el siguiente texto: HEILBRONER, R. Captítulo II "La revolución económica".

19 "Por su parte, la compleja maquinaria sociocultural no solo comporta un núcleo organizacional profundo (paradigmático) que manda/controla el uso de la lógica, la articulación de los conceptos, el orden de los discursos sino también....preconstrucciones intelectuales, estructuraciones doctrinarias." (MORIN, 1992, p. 21) 
Si se observa en conjunto lo recorrido, puede descartarse que el comentario acerca del carácter doctrinario y a la vez servil de la administración sea una provocación encaminada a abogar por un estatuto científico para ella - ya se glosaron algunos de los efectos desastrosos del pretendido o verdadero afán cientificista en administración. Una de las posibilidades que se genera a partir de la puesta en evidencia de dicho rasgo - arbitrariedad - y de la mencionada dependencia - servidumbre -, es que el saber se acerque no al título de ciencia, sino a la altura de una teoría (MUNOZZ, 2007, p. 228). A nivel de la construcción del conocimiento, para no mencionar la ruptura ideal con la ideología que se sirve de él actualmente, es deseable entre otras cosas la voluntad, de teóricos y prácticos, de leer las “situaciones cruciales” que continuamente se les presentan (POPPER, 1989,p. 27).

Para finalizar se quisiera señalar que el escrito no tuvo la pretensión de materializar una demanda marxista y menos aun una queja pesimista. Por lo menos no es esa la intención declarada del autor. Se trata, como se anunció inicialmente, de un ejercicio de crítica. Siguiendo las indicaciones de algún ilustrado, el escrito apela a la razón no como saber acabado sino como vía para la emancipación del ser humano ${ }^{20}$. Se trata de poner entre comillas lo que está entre las líneas del discurso administrativo. Por encima de sus preocupaciones por la efectividad de su discurso, del tamaño del nicho que este debería atraer, esta es una obligación que ningún profesor universitario, sin importar el saber que representa, debería rehusarse a cumplir.

\section{Referências}

BENNIS, W.; O'TOOLE, J. How business schools lost their way. Harvard Business Review, v. 83, n. 5, p. 96-104, 2005.

CASTILLO, M. Alberto Magno: precursor de la ciencia renacentista. Thémata, Sevilla, n. 17, p. 91-106, 1996.

FOUCAULT, M. Sobre la Ilustración. Madrid: Tecnos, 2004.

FREUD, S. (Ed.). Psicología de las masas y análisis del yo. Buenos Aires: Amorrortu, 2001. V. xviii.

GUSDORF, G. Los Modelos Epistemológicos en las Ciencias Humanas. Revista Psychologie, v. 43, n. 397, 1990.

JOHANSEN, O. Anatomía de la empresa: México: Limusa, 1992.

\footnotetext{
${ }^{20}$ Referencia a la máxima de Kant presente en "Respuesta a la pregunta: ¿Qué es la ilustración?”: “Aude sapere” (FOUCAULT, 2004, p. 75)¡Ten valor para servirte de tu propio entendimiento!
} 
KUHN, T. La estructura de las revoluciones científicas. México: FCE, 1994.

MARDONES, J. M. Filosofía de las ciencias humanas y sociales. Nota histórica de una polémica incesante. En: Filosofía de las ciencias humanas y sociales. Barcelona: Antropos, 1991.

MARTÍNEZ, M. Comportamiento humano. México: Trillas, 1989

MORIN, E. El método - El conocimiento del conocimiento. Madrid: Cátedra, 1994

MORIN, E. El método - Las ideas. Madrid: Cátedra, 1992.

MOUCHOT, C. Decisión y ciencias sociales. In MARTINET, A (Coord.). Epistémologies y sciences de gestion. Paris: Economica, 1990.

MUÑOZ, R. Aportes a una nueva fundamentación filosófica de la administración. 2008. 277p. Tesis (Doctorado en Filosofía). Escuela de Filosofía, Teología y Humanidades, Universidad Pontificia Bolivariana.

POPPER, K. Conocimiento objetivo. Madrid: Tecnos, 1989.

REALE, G.; ANTISERI, D. Historia del pensamiento filosófico y científico. Tomo Primero: Antigüedad y Edad Media. Barcelona: Herder, 1995. 